\title{
EL ESTUDIO DE LA IRONÍA EN EL TEXTO LITERARIO
}

\author{
Asunción Barreras Gómez \\ Universidad de La Rioja
}

\begin{abstract}
RESUMEN: Entendemos que la pragmática y la narratología ayudan a profundizar en el estudio de la ironía y su aplicación en un texto literario. Se analizarán los correlatos pragmáticos y la estructura dramática en que se encuadra la ironía. Se comentarán ciertas características de los participantes de la comunicación irónica. Además se mostrarán y se ejemplificarán las estructuras narrativas y lingüísticas así como los géneros que tipifican el uso de la ironía y sus rasgos principales. Finalmente, se entenderá que al estudiar la ironía habrá que buscar la evidencia lingüística que nos permita identificarla y, para comprender mejor esta figura retórica, habrá que interpretar su función estética.
\end{abstract}

ABSTRACT: Pragmatics and narratology are the basis of this study on irony. One understands some pragmatic aspects and the dramatic structure of the ironic texts. Several of the participants' characteristics in the ironic communication are studied. In addition to this, one learns about the narrative and linguistic structures in which irony is used as well as those literary genres dealing with irony. Finally, we also comment upon the linguistic evidence which allows us to identify irony as such. Moreover, one has to take into account that the interpretation of its aesthetic function is important in order to fully understand irony in the literary texts.

PALABRAS CLAVE: pragmática; narratología; ironía; implicatura; significado literal; contexto.

KEYWORDS: pragmatics; narratology; irony; implied meaning; literal meaning; context.

\section{La pragmática y su interés para el estudio de la ironía}

La importancia que los estudios de pragmática en lingüística (teoría de la relevancia de Sperber y Wilson de 1995, los estudios de cortesía de Brown y Levinson de 1987 y los estudios de la ironía de Sperber y Wilson y Lucker de 1997) ha adquirido en los últimos años ha permitido que se empiece a aplicar al estudio de la literatura. Entre los primeros autores que incidieron en esta línea de investigación destacan Richard Ohmann, Barbara Hernstein Smith y Mary 
Louise Pratt. Ohmann (en Martin 1986: 183) señala que los trabajos literarios son normalmente discursos sin reglas ilocutivas, es decir, actos sin consecuencias. Por tanto, el escritor imita los actos de habla en su obra como si fueran llevadosa cabo por alguien. Además, Pratt (1977) comenta que la teoría de los actos de habla es interesante porque permite hablar del lenguaje no solamente en lo que respecta a sus propiedades gramaticales, sino también respecto al contexto en el que se produce, de las actitudes e intenciones de sus participantes y sus relaciones, así como de reglas no dichas y convencionales que se comprenden cuando se da la comunicación. Pratt también añade que las ventajas de hablar de la literatura de esta forma para los trabajos literarios es que, como todas las actividades comunicativas, dependen de un contexto. Así, la forma en la que las personas escriben o entienden los textos literarios depende, en gran medida, de reglas y convenciones culturalmente compartidas, que se dan cuando se utiliza el lenguaje en un contexto (Pratt 1977: 86).

El interés de la pragmática para el estudio de la ironía se deja ver en que esta última se produce frecuentemente en el acto de comunicación. Kerbrat-Orecchioni (1980: 119 y 121) subraya la especificidad pragmática de la ironía y coincide con Fludernik (1993: 352), quien señala el aspecto pragmático de esta figura retórica: "Irony is always a pragmatic phenomenon of an implicational nature." Además una de las habilidades inferenciales que destaca Hutcheon (1995: 122) para la comprensión de la ironía por parte del receptor es la de inferir las creencias, intenciones o propósito comunicativo del emisor, y señala que esta habilidad pertenece al campo de la pragmática.

\section{La narratología y el estudio de la ironía}

La narratología nos ayuda a estudiar la estructura narrativa. En este campo cabe destacar especialmente el trabajo de Gerard Genétte (1972 y 1983) que, aparte de destacar el nivel de los hechos (historia) y el de los procedimientos utilizados para contar esos hechos (discurso), definió un tercero, el de la narración. Este tercer nivel incide en la representación en el texto de ciertas condiciones pragmáticas, ya que este tercer nivel es la representación de una narración ficticia dentro del texto. Además, la narratología muestra diversas figuras como el autor implícito, el lector implícito, el narrador o el narratario (con los estudios de Booth 1961, Prince 1996, Rimmon-Kenan 1983 o Gibson 1996) que se comunican entre sí y que se dan en los distintos niveles del texto. Es importante señalar estas figuras en el juego irónico creado por el autor porque se pueden contradecir y cada una de ellas puede tener una intención distinta. Habrá veces en las que la intención irónica del autor textual sea captada por el lector y no por el narrador; así, Fludernik (1993: 352) comenta que, si una de las figuras del texto utiliza la contradicción, en cualquiera de los niveles, se puede hablar de la ironía autorial. 


\section{El concepto de la ironía}

En general, se entiende que la ironía ocurre en el contraste entre aquello que se hace o dice y el mensaje que realmente se quiere transmitir (Muecke 1986: 33). La ironía se deduce de lo que dice y cómo lo dice el enunciador irónico, así como por el contexto en el que lo dice. No es un significado explícito que se pueda comprender directamente.

Al analizar la ironía, Grice consideró que quebranta la máxima de veracidad, equivalente a la violación de sinceridad de Searle (Lozano, Peña y Abril 1982: 192), por lo que, para conseguir una comunicación óptima, el enunciador ha tenido que transmitir alguna implicatura que compense la violación de esa máxima. Hutcheon (1995: 122) destaca la importancia de la pragmática para el análisis de la ironía y argumenta que la ironía conlleva ciertas destrezas deductivas. La primera se encuentra en el nivel semántico, puesto que el receptor debe detectar y reconocer la incongruencia entre lo que se dice y lo que no se dice. La segunda se halla en el nivel pragmático, ya que el receptor debe deducir la intención y el propósito comunicativo del enunciador. Finalmente, la tercera se encuentra en el nivel de desarrollo cognitivo social, es decir, la habilidad de inferir el conocimiento compartido del enunciador y el receptor del mensaje, así como la actitud del enunciador respecto de lo que dice.

Muecke (1986: 52-53) señala dos principios de la ironía que nos pueden ayudar a distinguirla. El primero es el principio de economía, que trata de la producción de un efecto supremo por medio de características poco extravagantes; es decir, que el enunciador irónico utilizará tan pocas señales como le sea posible. El segundo es el principio de gran contraste, que muestra la disparidad entre lo que se espera y lo que realmente sucede, de tal forma que, cuanta más disparidad se dé, mayor será la ironía. Por otro lado, Hutcheon (1995: 156) distingue cinco categorías que señalan la función de la ironía estructuralmente: varios cambios de registro, exageración/exposición incompleta, contradicción/incongruencia, literalización/simplificación y repetición/mención ecoica (Sperber y Wilson 1986).

Finalmente, Lozano, Peña y Abril (1982: 161), siguiendo ideas expuestas por KerbratOrecchioni (1980), comentan que hay dos mecanismos que permiten interpretar un enunciado como irónico. En el primero la expresión irónica se señala como extraña, ridícula y, por tanto, como no adecuada a la situación. El segundo tiene lugar con enunciados no marcados. Sin embargo, el enunciador considera que el destinatario posee la suficiente información como para saber que no se puede interpretar literalmente el mensaje y, por eso, no lo marca de ninguna manera. De esta forma el enunciado puede tener tanto una interpretación literal como irónica y, dependiendo de la información del destinatario, éste podrá interpretarlo de una forma u otra. 
Ohmann (1987: 29) destaca de la obra literaria que su lector debe descifrar los actos de habla que aparecen en ella, aunque el único acto de habla en el que participa directamente es el que ha denominado mímesis. Con este término quiere resaltar el hecho de que un lector construye al enunciador y las circunstancias que rodean a ese quasi acto de habla, ya que no tiene fuerza ilocutiva real, aceptando así "the willing suspension of disbelief" de Coleridge. Ohmann (1987: 34), Sterimer (en Lázaro Carreter 1987: 157) y Banfield (1982: 122) argumentan que estos quasi actos de habla se exponen al lector para su contemplación y no son realizados. Esto es lo que Austin denominó "etiolation" del lenguaje (en Levin 1987: 64) y uso parásito de la lengua en la literatura (en Domínguez Caparros 1987: 91). En este sentido, Bakhtin (en Lodge 1989: 103) destaca que la ausencia física del receptor en el contexto del acto de habla hace posible que el emisor ignore o suprima la dimensión dialógica del lenguaje, creando, de este modo, la ilusión de un discurso monológico, comentario que viene a apuntar hacia la misma idea sobre el lenguaje de la literatura. Sin embargo, hay opiniones como la de Pratt (1977: 26), que niega tal diferenciación entre el lenguaje ordinario y el literario. También Genette (1998: 31) comenta que el relato "no representa una historia," sino que "la significa mediante el lenguaje, con la excepción de los elementos verbales previos de esa historia (diálogos, monólogos), que tampoco imita, no porque no pueda, sino simplemente porque no lo necesita. Esto es así porque puede reproducirlos directamente o, para ser más exactos, transcribirlos." De esta manera, este último autor deja a un lado la idea básica de que los actos de habla que aparecen en un texto literario no se realizan, sino que el lector los contempla de forma pasiva.

Según Booth (1974: 10-12), para que el destinatario comprenda ese mensaje irónico, debe dar cuatro pasos. En el primero, el lector rechaza el significado literal y debe reconocer las incongruencias. En el segundo, piensa en posibles interpretaciones y explicaciones alternativas, que serán incluso contrarias a las del enunciado original. En el tercer paso, el lector toma una decisión sobre los conocimientos y creencias del autor. En el cuarto, finalmente, elige un nuevo significado válido. Leech (1974: 172) comparte con Booth la idea de su primer paso de rechazar el significado literal. Leech comenta que ese rechazo del significado se produce, bien porque sea inaceptable en la situación en la que se da, bien porque sea inaceptable en cualquier situación. Sperber y Wilson (1994 b: 165) también destacan que el receptor debe construir posibles hipótesis interpretativas sobre los contenidos y elegir el correcto; ideas equivalentes a las que destaca Booth en el segundo y cuarto pasos que se explicaron anteriormente. 


\section{Ironía e implicatura}

El proceso de la comprensión de la ironía tiene que ver con el descubrimiento de la/s implicatura/s que aparece/n en el texto. Leech y Short (1995: 294) definen la implicatura como "the 'extra meanings' that we infer, and which account for the gap between overt sense and pragmatic force" $y$, por tanto, se le puede considerar la base de la ironía ${ }^{1}$. Las implicaturas se pueden dar en el diálogo entre personajes o en el comentario autorial. Garrido Medina (1988: 153) destaca que con esta noción de implicatura "la expresión tiene un significado convencional, constante y unitario."Este significado es el que el lector adquiere en el cuarto paso antes citado de Booth (1974: 10-12). Sin embargo, para ello, el tercer paso anterior de Booth permite que se utilice el "componente inferencial" de la implicatura. Con este componente el receptor deduce la intención comunicativa del enunciador "empleando los datos veritativo-condicionales de las expresiones" y entendiendo que el enunciador coopera con el receptor. Es así como se da la buena comunicación. Según Sperber y Wilson (1994 a: 89), la comunicación correcta conlleva no solamente la codificación y descodificación de mensajes, sino también la provisión de suficientes evidencias como para poder valorar las intenciones del emisor del mensaje. Además, entienden que los fallos de comunicación son el resultado de la mala interpretación de esas evidencias. Por tanto, destacan también la provisión de esas evidencias por parte del enunciador para que el receptor pueda entender su actitud. Tiene que haber una cierta intencionalidad en el enunciador de querer ser entendido irónicamente. En este sentido Leech (1974: 171-172) subraya la intencionalidad del enunciador de la ironía, la no literalidad del mensaje irónico y la posibilidad de no comprender la ironía por parte de receptor. Esta posibilidad se evitaría si el enunciador utilizara suficientes evidencias que hicieran inferir el carácter irónico del mensaje.

Muecke (1986: 40) explica la estructura dramática de la ironía de la siguiente manera visual:

1. También puede ser la base de la metáfora ya que, como destaca Leech (1974: 174), tanto la ironía como la metáfora surgen de las mismas "linguistic source-violation of co-ocurrence conditions" y son modos distintos de interpretación de un texto por parte del lector. 
ROLES AND MESSAGES

SOCIO-CULTURAL CONTEXT

IRONIC TEXT

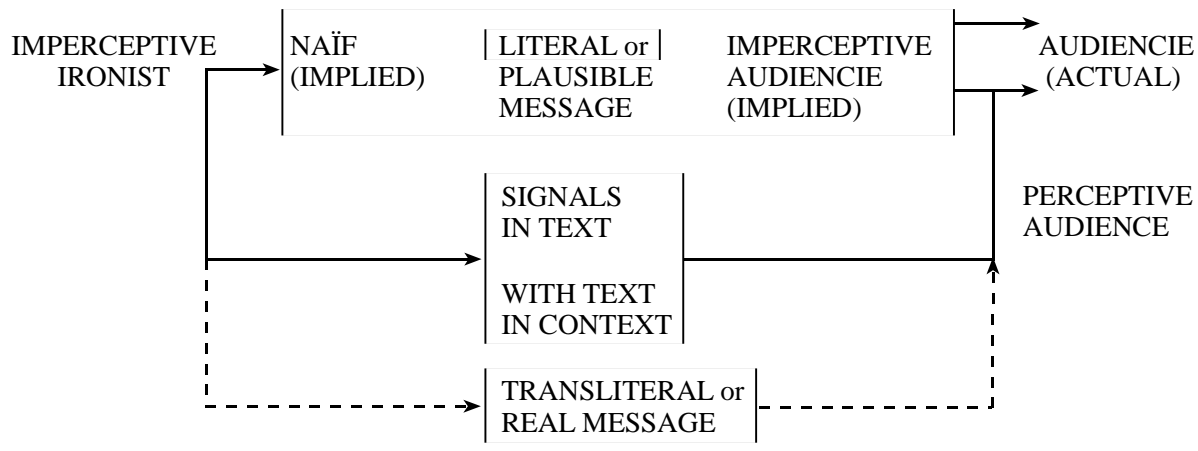

En el contexto sociocultural del momento el emisor irónico -en nuestro caso el escritor irónico- envía un mensaje, que es un texto irónico. Éste se puede entender literalmente de forma inocente por el lector que no percibe esa ironía. Pero también se puede entender irónicamente por aquel lector que perciba y comprenda la ironía, ya que ese lector "fill[s] in the gaps of sense with associative logic of his own" (Leech y Short 1995: 29) y se ayuda del contexto y de las evidencias e implicaturas del texto. Por lo tanto, habrá un significado doble, el literal e inocente y el irónico, que será apreciado por el buen lector (Leech 1974: 171).

Por otra parte, el texto irónico mostrará algunas evidencias en el texto, con el texto y en el contexto que permitirá que se entienda como irónico. Consideramos, en concreto, que las evidencias que se pueden encontrar en el texto, que transparentan su carácter irónico, no pueden ser otras, contenido aparte, que las estructuras narrativas y lingüísticas que señalaremos más adelante para clasificar y tipificar el uso de la ironía². El enunciador irónico utiliza unos estímulos que son la base para las hipótesis interpretativas (Sperber y Wilson 1994 b: 167) del receptor, en este caso del lector, así como para las señales del contexto.

2. Las cuales pueden incluir información editorial aneja y, además, son las que denotan si estamos ante, por ejemplo, un texto paródico. Véase más abajo. 
Es importante el contexto en el que se da el texto irónico, así lo señalan Ducrot y Todorov (1972: 326), Garrido Medina (1988: 148) y Fabb (1997: 251). Estos autores destacan varias características notables del contexto. Así, no significamos fuera de un contexto específico. Se trata del mayor recurso de evidencia para interpretar un contexto. Se considera el conjunto de premisas empleadas en la interpretación de un enunciado (Garrido Medina 1988: 148), pero también puede ser considerado como un marco físico y cultural (Fabb 1997: 253). El contexto debe ser conocido por los interlocutores que tienen que ver con la producción y comprensión del enunciado para garantizar que el contexto ayudará a comprender el texto irónico.

Sperber y Wilson formulan cinco hipótesis que justifican la importancia del contexto en la comprensión:

[...] the context for the comprehension of an utterance consits of the assumptions expressed and implicated by preceding utterances, plus the encyclopaedic entries attached to any concepts used in these assumptions and in the utterance itself, plus the encyclopaedic entries attached to any concepts used in the assumptions contained in the encyclopaedic entries already added to the context. (Sperber y Wilson 1994 b: 136)

En el caso de la comprensión de la ironía debemos tener presente las presuposiciones dadas por conocidas por parte del enunciador y las implicaturas que hayan podido aparecer en lo ya dicho por éste, así como los conocimientos unidos a cualquier concepto de las presunciones que se vean asociadas a los conocimientos ya unidos al propio contexto. Todo esto puede significar un gran esfuerzo de procesamiento por parte del receptor, así como la necesidad del tiempo suficiente para el procesamiento de datos.

Por otra parte podemos mencionar el hecho de que la propia literatura puede servir de contexto lingüístico y cultural, ya que las obras literarias pueden comprenderse por medio de sobrentendidos y conocimientos de convenciones literarias o culturales (Domínguez Caparros 1987: 100). Éste es el caso de la parodia, puesto que el lector tiene que colocar el texto parodiante en el contexto literario y cultural para descubrir los ecos intertextuales literarios y el texto parodiado al que se hace referencia irónicamente.

Teniendo en cuenta las evidencias en el texto y el contexto sociocultural, el receptor -el lector- descubre el mensaje real, que es irónico. En el caso de un relato, por ejemplo, el lector puede entender la ironía desde el principio o descubrirla junto al personaje u otra víctima de la ironía. En relación con esto cabe destacar, como han señalado Sperber y Wilson (1994 b: 165), que el éxito de la comunicación depende también de la habilidad del receptor en inferir la intención, irónica en este caso, del enunciador. 


\section{Los vehículos de la ironía: estructuras narrativas, lingüísticas y géneros literarios}

La ironía se puede objetivar hasta cierto punto en la composición del texto con algunas estructuras narrativas y lingüísticas y en algunos géneros, como explicaremos más adelante. En este sentido, Halle (1989: 75) destaca la importancia de la comprensión de la forma para valorar correctamente un texto literario. Las siguientes estrategias ayudan a clasificar y tipificar el uso de la ironía, de tal forma que, por ejemplo, se puedan apreciar voces que se dan de manera contradictoria en el mismo texto y den lugar a la aparición de la ironía.

\subsection{Discurso directo}

Esta forma de discurso está señalada tipográficamente con comillas o, a veces, también con un párrafo escrito aparte. Leech y Short (1995: 318) señalan que un emisor utiliza el discurso directo para expresar lo que otra persona ha dicho. Este segundo emisor, por tanto, cita las palabras textuales entre comillas y no utiliza un "que" que introduzca una oración subordinada. Estos autores también destacan el hecho de que en la forma escrita no se pueda reproducir la entonación de la otra persona para dejar clara su actitud. Sin embargo, comentan el esfuerzo de los novelistas de superarlo cuando utilizan la ortografía convencional para sugerir ciertas pronunciaciones (Leech y Short 1995: 321) y caracterizar así al personaje en cuestión.

Banfield (1982: 116) destaca que esta forma es especialmente "addressee-oriented" y que semánticamente resalta la relación yo-tú, puesto que cuando aparece la segunda persona del singular en un texto literario se está implicando también a la primera persona del singular, el yo que relata. Además señala que "[... it] present[s] or imitate[s] speech" (Banfield 1978: 309) y que "[... it] represents the act of verbal communication" (Banfield 1973: 29).

Rimmon-Kenan (1983: 106) considera que el estilo directo es una forma mimética, especialmente con los monólogos y los diálogos. Fludernik (1993: 31) también destaca la capacidad mimética de este discurso y señala que ayuda a clarificar y comprender la empatía, la especificidad, el realismo, la distinción estilística o la reproducción. Sin embargo, a pesar de la ilusión de dar a entender la transcripción de un diálogo, por ejemplo, en realidad encontramos evidencias que delatan al narrador, que para Leech y Short (1995: 322), son "the quotation marks and the introductory reporting clause." 
García Landa (1998: 339) destaca varias funciones en el discurso directo como es el mostrarse a uno mismo como parte de la acción, caracterizar a los personajes o transmitir parte de la acción a través de lo que dicen los personajes.

Lozano, Peña y Abril (1982: 150) comentan que se puede ironizar con las palabras de otro enunciador utilizándolas literalmente, pero de forma burlona. Por ejemplo, cuando se mimetiza el gesto del locutor citado de forma exagerada. De esta manera el segundo enunciador puede desacreditar esas palabras y a su locutor de diversas formas, pero sin salirse de los parámetros del discurso directo. Sperber y Wilson (1994 a: 102-103) apuntan ideas parecidas al decir que los enunciados irónicos pueden ser totalmente literales (o no literales) siempre que el pensamiento sea atribuido por el enunciante a otro locutor. Estos autores consideran que la ironía, por tanto, conlleva una expresión implícita de la actitud de burla o desprecio del enunciador.

Otra forma en la que se puede utilizar la ironía se da al citar directamente el discurso de un enunciador, pero sacando su discurso fuera del contexto primario. De tal manera ese discurso adquiere un significado distinto, irónico y contrario a su significado inicial (Lozano, Peña y Abril 1982: 149).

La cita de una enunciación aparece con la elección de sintaxis y léxico del primer enunciador. A veces ese léxico y esa sintaxis aparecen con errores (Banfield 1982: 248). Se pueden citar los errores que personajes extranjeros cometen al utilizar en inglés. Esto lo puede hacer un escritor para reproducirlo literalmente e intentar ser realista. Sin embargo, también se puede hacer para ironizar y dar un retrato burlón de un personaje.

Un ejemplo del uso de discurso directo en Nabokov tiene lugar en "The Dragon," ya que más que utilizarse el discurso indirecto o el estilo indirecto libre el autor utiliza el discurso directo para retratar a los personajes de la ciudad que visita el dragón y el resultado suele ser irónico. Un caso es, por ejemplo, cuando el dueño de la compañía de tabaco Miracle quiere pegar anuncios de su compañía en el vientre del animal, a pesar de saber que es un dragón: "Set up the ladder," said the factory owner. "I'll do the pasting myself" (CS 128). El autor ironiza sobre la competencia propagandística utilizando la predisposición al trabajo del personaje.

\subsection{Cambio de registro o código lingüístico. Utilización de dialectos}

Leech (1974: 8) y Leech y Short (1995: 167) destacan del dialecto la cualidad de estar lingüísticamente marcado dependiendo de los lugares geográficos, clases sociales o secciones de la comunidad en los que se hable. La utilización del dialecto por el escritor resalta su desviación y diferencia del lenguaje literario que está 
utilizando en su obra hasta ese momento (Leech y Short 1995: 170), lo cual le permite mostrarse como realista y costumbrista, registrando y dando a conocer el lenguaje real hablado. Sin embargo, como en otras ocasiones, el escritor puede dar una imagen irónica del personaje que utiliza ese dialecto.

Leech (1974: 9) considera el registro como el uso del lenguaje que se da dependiendo de la situación, y, como en el dialecto, se pueden apreciar características típicas de vocabulario, gramática e, incluso, pronunciación. Leech y Short (1995: 106) destacan la utilización del registro como recurso de la ironía. Comentan que la ironía tiene lugar cuando se mezclan las expresiones cultas y vulgares en la misma frase, lo que demuestran con un ejemplo tomado de la obra The Pupil de Henry James: "When Mrs Moreen bethought herself [culto] of this pretext for getting rid of [coloquial] their companion". Esta disparidad de registros crea un efecto burlón e irónico.

En los textos literarios también se puede utilizar el cambio de código lingüístico para introducir un personaje y caracterizarlo por ese nuevo código o para presentar una voz ajena a la del autor, que conserva la propia lengua. Las lenguas (dialectos y registros), aparte de relacionarse con los contenidos y dar lugar a problemas de traducibilidad, por ejemplo, intervienen también en la caracterización de los participantes en la comunicación. De esta manera, un cambio de código indicará un cambio de postura, de identidad, etc. (Lozano, Peña y Abril 1982: 153). Evidentemente, ese cambio puede ser irónico. Así, por ejemplo, la utilización que hace del ruso la institutriz suiza que aparece en "A Bad Day" de Nabokov constituye una ironía acerca del hecho de que no sepa hablar ruso a pesar de los muchos años que ha estado viviendo en Rusia.

Bakhtin considera que las expresiones típicas de un grupo (de cualquier tipo: nacional, social, etc.), al aparecer en un texto, pueden dar a entender la participación por parte del enunciador o grupo que las utiliza del "horizonte ideológico-verbal" de esa lengua (en Lozano, Peña y Abril 1982: 152). Sin embargo, en términos generales, podemos obtener también otra conclusión distinta, más interesante, desde el punto de vista del recurso de la ironía. Cuando el enunciador se sale notablemente de lo que el lector considera la forma normal de contar un hecho o del estilo normal de ese enunciador, el lector debe sospechar que está tratando con el recurso de la ironía.

\subsection{Colocación inusual de palabras}

Leech y Short (1995: 106 y 278) comentan como forma del recurso irónico la colocación extraña e inusual de las palabras. Por un lado, esta colocación de palabras de forma inusual puede sorprender nuestras expectativas. De esta manera, la ironía 
se da en lo que denominan "collocative clash", y como en el caso de la utilización irónica de los registros, se produce al chocar las convenciones de lo educado y correcto con las del eufemismo.

La ironía puede surgir de la incongruencia en la forma en la que se unen las palabras en las frases. Estos autores ponen los siguientes ejemplos, también extraídos de la obra The Pupil de Henry James: "fat jewelled hand" y "soiled gants de Suède". Las poco atrayentes palabras "fat" y "solid" influyen para que las palabras a las que caracterizan, "jewelled" y "gants de Suède", se presenten como pretenciosas.

También se puede destacar un tipo de ironía que juega con las expectativas y frases hechas. Hamamoto (1997: 267) afirma lo siguiente: "Normally for a verbal irony to occur, the prior cognition is mapped into a linguistic form. However, at times the re-cognition of reality can be mapped into a linguistic form as well". Este autor lo ejemplifica con casos como: "Friends are always there when they need us" o "A sitch in time saves none" (Hamamoto 1997: 268) o "antes de salir, dejen entrar".

Por otro lado, destacamos en esta sección el juego de palabras y los anagramas, una utilización del lenguaje que es constante en la obra de Nabokov. El lector se tiene que fijar en el lenguaje utilizado, valorar la forma y el contenido de las palabras y descubrir estos acertijos propuestos por el enunciador, de tal forma que, si no los capta, el lector, al menos temporalmente, sería la víctima de la ironía.

\subsection{La parodia}

La parodia es una imitación en la que se enfatizan las características estructurales o temáticas de lo que se quiere destacar, la obra de un escritor o un género. Este énfasis permite resaltar esas características de manera que impliquen lo contrario de lo que dan a entender. Marchese y Forradellas (1986: 311) caracterizan la parodia como "la imitación consciente de un texto, de un personaje o un motivo" primitivo, que se hace de forma irónica para poner de manifiesto el distanciamiento y crítica al modelo primigenio. La parodia también utiliza un mecanismo parecido al de las comillas de distancia, ya que se trata de la incorporación de un texto parodiado a un texto parodiante. Supone la desviación de una norma literaria y su introducción como material del texto paródico. Se trata de una forma intertextual en la que se desacredita el texto al que se alude. Puede tratarse de una alusión a un texto, un género o una norma que se destaca y enfatiza, y supone un distanciamiento, puesto que se deja claro que el texto parodiante no comparte el significado del texto o forma parodiada a que se alude. Así, la norma o el contenido del texto parodiado aparece en el texto parodiante y el enunciador establece un distanciamiento, una crítica o un tono burlón al respecto (Lozano, Peña y Abril 1982: 162 
y Hutcheon 1981: 143). En este sentido, Martin (1986: 180) resalta que, en tanto en cuanto hay dos códigos en el mismo texto, hay dos significados en la parodia: el serio del significado original y el paródico.

Se debe rechazar el significado superficial y literal para reconstruir uno más profundo. El lector se debe dar cuenta de que el estilo, la obra o el autor al que se alude se distorsiona de forma burlona. La parodia, por tanto, apela a la competencia literaria y al conocimiento literario del lector. Con la competencia literaria se aprecian los estilos, formas, convenciones o símbolos de las obras. Brumfit y Carter (1986: 18) definen la competencia literaria como "[...] an interesting combination of linguistic, socio-cultural, historical and semiotic awareness", aunque hay autores como Aguiar e Silva que, aparte de centrarse en la competencia literaria (Aguiar e Silva 1980), también hablan de la experiencia literaria (Aguiar e Silva 1979: 39), constituida por estructuras lingüísticas, poéticas, estilísticas, etc. La competencia literaria permite una sensibilidad especial para apreciar el uso de la lengua, tratándose también, del conocimiento literario de estilos, autores y obras que le permitirán al lector apreciar los ecos intertextuales con los que juega la parodia, puesto que en ésta se debe identificar el texto parodiado y su autor dentro del texto parodiante (Genette 1998: 100), de nuevo surge la idea del ecoismo de la ironía. Por esta razón, Booth (1974: 123) destaca que "in reading parody, we make use of external reference to other authors in order to understand how the parody attacks those same authors: the thing referred to, externally, to assist in comprehension, is the same thing referred to, externally, as the object of ridicule". En consecuencia, el lector se hace consciente del rasgo intertextual de la parodia y sabe que debe tener presente su experiencia de otros textos literarios. Es lo que se denomina hipercodificación (Eco 1979: 81 y Lozano, Peña y Abril 1982: 20). Además, se destaca que cada lector tiene su propia competencia literaria, por lo que el significado de un texto puede variar dependiendo de su competencia literaria (García Landa 1998: 421).

Un relato típicamente paródico es "The Canterville Ghost" de Oscar Wilde. El texto parodiante del autor humaniza al fantasma y utiliza un tono burlón para con la literatura que recoge historias de fantasmas, desmitificándolas. En este relato aparece un fantasma que se siente débil o que utiliza disfraces para asustar. Además, se ve acosado por la familia a la que quiere atemorizar. Por ejemplo, los gemelos de la familia Otis le tienden trampas y Mrs Otis limpia la famosa mancha de sangre de Canterville con el efectivo quitamanchas industrial Pinkerton.

Consideramos que la parodia puede utilizar formas convencionales y clausuradas para ironizarlas y desautomatizarlas. El escritor que utiliza la parodia de esta manera podría considerarse un "epígono", que Posner (1987: 134) define como "un escritor... [que] intenta todavía desautomatizar por medios que ya han sido 
codificados códigos ya caducos". Un ejemplo sería la utilización de la forma "mock heroic" del siglo XVIII. Leech (1974) destaca de esta forma que es un método de ataque con el que aparentemente se celebra una acción. En el "mock heroic" se utiliza la forma de la poesía épica de grandilocuente sintaxis y léxico, que es una forma convencional y clausurada. El autor la desautomatiza aplicándola a temas vulgares, que no son poéticos, dándose así, posiblemente, un efecto irónico. Al desautomatizar, el escritor defamiliariza al lector con las convenciones de un género. Shklovsky señala que tanto la parodia como la sátira consiguen mostrar esos mecanismos convencionales y defamiliarizar las formas que siempre se han utilizado (en Martin 1986: 49).

\subsection{Discurso indirecto}

En el discurso indirecto se expresa lo que otro enunciador ha dicho transformando gramaticalmente el enunciado del segundo enunciador. Esto supone la eliminación de ciertos rasgos del enunciado. Se cambian los pronombres personales, los tiempos verbales y los adverbios de lugar y tiempo, de tal forma que lo que se dice que dijo el primer enunciador queda totalmente integrado en el nuevo texto y en sus condiciones de enunciación. Sin embargo, precisamente por esos cambios, se considera menos objetivo que el discurso directo (Lozano, Peña y Abril 1982: 151 y Leech y Short 1995: 318) y, por tanto, más interpretativo.

Banfield (1973: 3) destaca cuatro diferencias gramáticales, válidas para el inglés y mutatis mutandis para el español, entre el discurso directo e indirecto: "(i) a subordinating conjunction that introduces indirect speech; (ii) the verb of indirect speech undergoes sequence of tense rules (which affect verbs in many types of subordinate clauses); (iii) the grammatical person of pronouns with the same referent in the main and embedded clauses of indirect speech is identical; and (iv) the demonstrative elements which refer to the time or place of the quoted speech act differ in direct and indirect speech". Esta autora concluye diciendo que el estilo indirecto se da cuando un verbo de comunicación toma una frase como objeto directo (Banfield 1973: 17). Destaca del discurso indirecto que sus características hacen que su naturaleza sea más interpretativa que imitativa (Banfield 1982: 62). Para esta autora, el segundo enunciador interpreta el contenido de lo dicho por el primer enunciador. Para ello, el segundo enunciador utiliza una forma proposicional, evita todas las características del discurso del primer enunciador o traduce ese discurso a una forma descriptiva, por ejemplo. Fabb (1997: 263) destaca del estilo indirecto la posibilidad de atribuir pensamientos a los personajes, así como la de retratar las relaciones de esos personajes con sus 
pensamientos junto con verbos como believe, think, etc. Esto significa que un texto literario puede describir la vida interna mental de los personajes.

El hecho de que en el estilo indirecto se cite el discurso de un primer enunciador abre la puerta fácilmente a la ironía, ya que, como destacan Sperber y Wilson (1994 b: 238) ésta es la interpretación del pensamiento de otro enunciador distinto al que está hablando. Ambos autores argumentan que el estilo indirecto consigue relevancia por informar al receptor de lo que piensa el enunciador, y, por tanto, son enunciaciones ecoicas, puesto que se hacen eco del pensamiento o la enunciación de otra persona. El enunciador expresa su propia actitud, normalmente de rechazo o burla, junto con el pensamiento o enunciación que repite. Además, Lozano, Peña y Abril (1982: 165) y Fludernik (1993: 77) destacan que, al utilizar la ironía, el segundo enunciador marca un distanciamiento. Consigue que lo que dice no se le atribuya a él, puesto que muestra lo ridículo o lo absurdo de esa cita y, por ello, la hace explícita, utilizando una forma indirecta.

Nabokov utiliza este discurso indirecto en "Details of a Sunset" para mostrar el mundo subjetivo del personaje central. La ironía aparece en este relato porque el contexto en el que se utiliza esta forma no es la realidad objetiva, que es lo que parece, sino la realidad subjetiva del protagonista. Sin embargo, el lector no se hará consciente de la contradicción entre los dos mundos, el objetivo y el subjetivo, hasta llegar al final del relato, y la víctima momentánea de la ironía será el lector.

\subsection{Estilo indirecto libre}

Se le denomina style indirect libre en la crítica francesa, y free indirect style o free indirect discourse en la inglesa. Charles Bally lo clasificó como indirecto porque pensó que se derivaba del discurso indirecto, y lo clasificó como libre porque no contenía conjunciones. Este autor entendió que era un estilo y no una forma gramatical, ya que no seguía las reglas del uso normal del lenguaje y se daba solamente en los textos escritos. La crítica alemana lo denominó erlebte rede, "lenguaje experienciado", y Bakhtin lo llamó dual-voiced discourse, al entender que aparecen las voces del narrador y del personaje en el mismo discurso (Martin 1986: 138). También lo han denominado "represented speech and thought" autores como Jespersen (en Banfield 1978: 289) y Banfield (1978: 289). Esta última autora destaca de esta forma que "[...it] represent[s] or imitate[s] ... speech and conscious" (Banfield 1978: 309). Además, no presupone un narratario a no ser que se dirija a un tú, como narratario. 
Otros autores como Lozano, Peña y Abril (1982: 152) y Leech y Short (1995: 325) comentan que se considera el estilo indirecto libre la versión más libre de la forma indirecta. Se encuentra en una posición media, ya que no es la reproducción exacta del discurso original pero está más allá de la reproducción indirecta de éste. Según Fludernik (1993: 74), se halla más cercano al estilo indirecto desde el punto de vista gramatical, y más cercano al discurso directo desde el punto de vista sintáctico y mimético. Se trata de caracterizar al personaje en el discurso del narrador con las palabras y pensamientos de ese personaje. Por esta razón, Rimmon-Kenan (1983: 116) resalta la característica polifónica de este estilo, ya que se trata de la yuxtaposición de dos voces, al menos, en el propio texto y, por tanto, se revela como una "doble-edged nature" y "double-edgedness".

El estilo indirecto libre no posee una oración introductoria que indique que se vaya a utilizar, ni está introducido por un verbo del tipo verba dicendi que señale que se vaya a contar algo. Asimismo tampoco se encuentra un aparente narratario de esa enunciación (Banfield 1973: 33 y 1978: 291). Stanzel (1986: 194) comenta que el estilo indirecto libre muestra una perspectiva interna; sugiere inmediatez y la ilusión de estar viendo directamente los pensamientos del personaje. Además, se aproxima al lenguaje coloquial, que es sintácticamente más simple. Se pueden incluir, por ejemplo, las indecisiones o el dialecto del personaje, pudiendo dar lugar a la ironía, lo que señala la "mimetic closeness" con respecto al discurso o pensamiento original (Fludernik 1993: 236).

Con el estilo indirecto libre se transmiten los contenidos del primer enunciador e, incluso, sus propias expresiones para caracterizarlo en el discurso del segundo enunciador. El objetivo no es solamente reproducir el sentido del enunciado del primer locutor, como se hace en el discurso indirecto, sino también destacar la forma en la que expresa ese enunciado. Esta última característica podríamos relacionarla con la idea de Bakhtin del narrador como "portador de un horizonte ideológico verbal" (en Lozano, Peña y Abril 1982: 138). El narrador caracteriza el personaje al que se refiere con la lengua en la que se manifiesta y asume como propio el mundo sociocultural de dicho personaje. Entendemos que el estilo indirecto libre permite caracterizar al personaje con la lengua en la que éste se expresa, y, de esta manera, el narrador pasa a ser el portador del horizonte verbal del personaje. Leech y Short (1995: 326) destacan que esta habilidad del narrador de utilizar las palabras del personaje manteniendo una posición de dominio en la narración hace del estilo indirecto libre "an extremely useful vehicle for casting an ironic light on what the character says". Esta misma característica también la resaltan Lozano, Peña y Abril (182: 163), Rimmon-Kenan (1983: 114) y Fludernik (1993: 76). Estos autores enfatizan el hecho de que se mezcla el discurso del narrador y el del personaje de tal forma que el primero se mofa del segundo. El narrador se 
apropia de las expresiones y los pensamientos del personaje y, al enunciarlos, se burla éstos o los critica para dar un retrato irónico de dicho personaje, aunque éste no tiene por qué ser siempre la víctima de la ironía. Respecto a la mezcla del discurso del narrador y personaje, Stanzel comenta que este estilo puede ser una visión dual de los hechos desde la perspectiva de ambos, y dice que

[...] the presence of the narrator as the tangible embodiment of the mediacy of narration, on the one hand, and the illusion of immediacy by the reflection of the fictional reality in the consciousness of a figural medium or a reflectorcharacter, on the other, come together in free indirect style. (Stanzel 1986: 191)

Banfield (1973: 29) y Rimmon-Kenan (1983: 114) comentan que la capacidad de reproducir las palabras y los pensamientos del personaje en el discurso del narrador hace que el estilo indirecto libre sea una forma adecuada para articular la prosa denominada "stream of consciousness", de la que Leech y Short (1995: 251) afirman que es la manifestación más conocida del estilo indirecto libre y que, como se sabe, impulsó significativamente James Joyce. Por otro lado, Nabokov (1984: 280) comenta que no se ha reconocido internacionalmente que fuera Tolstoi el que utilizara este método de expresión mucho antes que James Joyce $^{3}$. Con todo, Nabokov también matiza que en Tolstoi este procedimiento es rudimentario, mientras que en James Joyce se desarrolla hasta alcanzar la crónica objetiva. En general, se puede decir que se trata de una técnica característica de las obras novelísticas de la primera parte del siglo XX.

Nabokov utiliza el estilo indirecto libre en "Perfection" para mezclar el mundo subjetivo del personaje principal con el objetivo del relato. Al hacerlo sin avisar previamente del cambio de nivel narrativo, el lector no entiende bien lo que sucede alrededor del protagonista hasta el final, en el que vuelve a aparecer el mundo objetivo que rodea al personaje. La víctima temporal de ese juego irónico ha sido el lector, que se ha sentido tan confundido y desorientado con la realidad objetiva como el protagonista del relato.

\subsection{Narración débil}

Llamamos así a un tipo de narración en la que el narrador, como tal figura, se muestra débil en su labor, puesto que se contradice, no cuenta todo lo que ocurre

3. En cualquier caso, se suele citar como propulsor a Edouard Dujardin y su Les lauriers sont coupés. 
o aparece junto a otros narradores. Ha de ser, pues, el lector atento el que tiene que deducir lo que sucede. En este sentido, el autor tendrá unos "artistic criteria of relevance" (Leech y Short 1995: 155) para utilizar u omitir información (paralipsis en la terminología de Genette 1998: 47) que el lector tendrá que cubrir con sus deducciones.

Una estructura narrativa que se puede utilizar es la que Stanzel (1986: 144) denomina reflector-character. Este narrador refleja el mundo que su consciencia percibe, siente y nota a su alrededor, pero de forma silenciosa, ya que nunca narra. Este narrador no verbaliza sus percepciones o sentimientos; el lector parece encontrarlos directamente. La historia se cuenta a través del punto de vista y la consciencia del personaje. Por tanto, el lector se ve limitado por el conocimiento y experiencias de este narrador.

Un tipo de narrador que cabe dentro de esta clasificación es el que Booth (1996: 152) denomina unreliable narrator. Se trata de un narrador que no actúa de acuerdo con las normas del texto. El lector tiene que juzgar por sí mismo si lo que le cuenta el narrador es cierto o no, e incluso imaginar ciertos detalles de una descripción que el narrador no le da. Se trata también de una visión limitada en la que se encuentra el lector. Rimmon-Kenan (1983: 100) destaca el hecho de que éste no puede fiarse de el narrador, y caracteriza este tipo de narración diciendo: "The main sources of unreliability are the narrator's limited knowledge, his personal involvement, and his problematic value-scheme".

También destacamos aquí la teoría de los niveles narrativos (Genette 1998: 57). Aunque es evidente que el relato introducido está subordinado al relato marco porque le debe la existencia y se apoya en él, a veces resulta difícil saber qué nivel de ficción es el primario y cuál el secundario, debido a la estructura de la obra. De nuevo el lector tiene que decidir de qué nivel se trata y si se trata de una muestra de humor, fantasía o ironía.

Un ejemplo de este tipo de narración débil se recoge en The Golden Notebook de Doris Lessing. En esta novela hay varios cuadernos, con la función de trabajar como narraciones breves, que están basados en distintas facetas de la vida de la protagonista. Estas historias están fragmentadas y mezcladas. En cada uno de estos cuadernos se encuentran varias historias, solapos de historias e, incluso, historias contradictorias entre las que el lector debe elegir la correcta. Además, el lector descubre que la primera frase de The Golden Notebook, "The two women were alone in the London flat" (Lessing 1972: 554), es la primera frase del libro que la protagonista va a escribir dentro de la novela que el lector está leyendo. Este artificio puede, incluso, borrar las fronteras entre la ficción y la realidad y confundir al lector. 
Otro ejemplo es The Eye, una novela corta de Nabokov. El protagonista, Smurov, intenta suicidarse pero sigue viviendo, aunque entiende la vida como si hubiera muerto. Es al final de la novela cuando el lector descubre que está vivo y que el narrador es el propio Smurov. Nabokov suele utilizar narradores homodiegéticos. Sin embargo, hay veces en las que juega con estas categorías. Este último aspecto lo trabaja en la novela The Eye, donde el narrador engaña en un principio al lector porque aparecen diversos puntos de vista en tercera y primera persona. El narrador se manifiesta como heterodiegético, pero al final el lector descubre que de quien el narrador está hablando es de él mismo, y pasa a ser homodiegético.

Un último ejemplo es el relato "The Babysitter" de Robert Coover, donde aparecen una serie de narraciones de lo que está ocurriendo en la historia que son contradictorias. Sin embargo, no se ofrece ninguna explicación sobre esas contradicciones ni hay ninguna prioridad de credibilidad entre ellas. No existe una verdad final en el relato, por lo que permanecen contradictorias. El lector tiene que incorporar la contradicción como parte de la descripción en dicha narración breve.

\subsection{Enunciación enunciada}

Para Jakobson (1957), los shifters, deícticos o conmutadores, son símbolosíndice que se distinguen por reenviarse obligatoriamente "al mensaje" e implicar, por tanto, una referencia al proceso de la enunciación (Lozano, Peña y Abril 1982: 95). Esto tiene que ver con la representación textual de la enunciación, denominada "enunciación enunciada" por Greimas y Courtés (1979: 128). Las personas /yo/ y /tú/ que aparecen en esos textos, escritos u orales, son personajes del enunciado y no de la enunciación. Estas personas serían equivalentes al narrador y narratario de la terminología de Genette (1989).

En la enunciación enunciada se aprecian cambios de tiempos verbales y de casi todos los morfemas gramaticales, que dan lugar a un tipo particular de relación comunicativa. Es lo que se ha designado estructura reflexiva del enunciado o texto, por lo que éste se autoalude y define la situación en la que se da (Lozano, Peña y Abril 1982: 110). Leech y Short (1995: 231) resaltan que hay ejemplos en la literatura donde los textos tienen una retórica de alusión al interlocutor, reflejan las exigencias de la codificación del mensaje y dan la impresión de espontaneidad y vigor. Hay veces que estas alusiones a la codificación del mensaje aparecen directamente en el texto, y otras en las que utilizan los paréntesis.

Lozano, Peña y Abril (1982: 112) destacan que los procedimientos de la enunciación enunciada se realizarán fundamentalmente a través de las formas de localización espacial y temporal (deícticos, anafóricos y tiempos verbales 
comentativos o narrativos) y de las formas de personalización y despersonalización de la enunciación. Mencionan el cambio de nivel porque el hecho de adquirir una forma u otra hace que existan tipos distintos de relación, afectando la manera de ser percibida. De esta forma, se observarán casos, por ejemplo, en los que la enunciación enunciada se conmuta en la enunciación objetiva, o viceversa. Estas conmutaciones del discurso implican cambios de tiempos, cambios de personas o cambios en las localizaciones espaciales.

Dentro de este estilo se pueden apreciar ejemplos de metanarración o metadiscurso, en donde el narrador comenta la narración y hace desaparecer la frontera que distingue el nivel diegético y el metadiegético (Lozano, Peña y Abril 1982: 141). Los ejemplos metadiegéticos no sólo están fuera del mundo diegético de la narración, sino que se pueden referir al hecho mismo de narrar. Esta idea tiene que ver con el comentario de Fabb (1997: 207), cuando dice que "[...] it is also possible for a storyteller to link the narrated and the narrating worlds in the course of the story". De tal manera, argumenta este autor que el narrador llega al mundo del lector $y$, al hacerlo, consigue que éste se transforme en personaje.

Esta forma de enunciación enunciada se relaciona con el concepto romántico de ironía, que se desarrolló a finales del siglo XVIII y principios del siglo XIX. Friederich Schlegel, uno de los representantes de la ironía romántica, comenta que hay dos fases contrarias y complementarias de la creación artística. En la primera fase el artista es inocente, entusiasta e imaginativo, mientras que en la segunda fase se muestra reflexivo, consciente, crítico e irónico. Es una explicación que nos lleva a pensar en los cantos de inocencia y experiencia de William Blake en la literatura inglesa. Muecke (1986: 73) destaca: "In Romantic Irony the inherent limitation of art, the inability of a work of art, as something created, fully to capture and represent the complex and dynamic creativity of life, is itself imaginatively raised to consciousness by being given thematic recognition". Schlegel considera como grandes ejemplos de esta ironía romántica Don Quijote, Tristram Shandy y Jaques le fataliste, puesto que integran el proceso de composición dentro del producto estético y se presentan tanto como arte como (limitación de) la vida (Muecke 1986: 25).

Consideramos que dentro de esta línea se pueden incluir también los textos literarios que se enmarcan dentro de la denominada metaficción. La literatura metaficcional tiene que ver con las convenciones de la escritura de una narración, por lo que se le llama novela narcisista o reflexiva. Su texto expone el proceso de su construcción. Sin embargo, aunque aparezca reflejada cierta ironía ante la pretensión de reflejar la realidad como hace la novela realista, su objetivo no es dicha ironía, sino mostrar las limitaciones de esa novela realista para reflejar la realidad y, por tanto, parodiarla, así como presentar la imposibilidad de la novela para reflejar la 
realidad. Un ejemplo de relatos metaficcionales donde se utiliza esta forma de la enunciación enunciada lo constituye el ciclo de relatos titulado Lost in the Funhouse de John Barth. En el siguiente ejemplo, tomado de "Autobiography", vemos cómo el narrador se muestra autoconsciente en su labor narrativa utilizando la enunciación enunciada:

\section{I must compose myself.}

Look I am writing. No, listen, I am nothing but talk. (Barth 1988: 36)

\section{Conclusión}

Como se habrá observado, junto con esta tipificación de estructuras lingüísticas y narrativas que se han señalado, como el discurso directo, el uso de comillas de distancia o el cambio de código lingüístico, se incluyen también dos géneros literarios como son la parodia y el que hemos denominado narración débil. Otros autores como Lozano, Peña y Abril (1982: 149-166), al hablar de la palabra propia y ajena y de la identificación y la distancia, distinguen entre las citas expresas y las citas no expresas. En las citas expresas incluyen el discurso directo, el discurso indirecto y el estilo indirecto libre, y en las citas no expresas hablan de las citas implícitas y las figuras de la ironía, la burla y la parodia ${ }^{4}$.

Hemos considerado más interesante para el propósito de este estudio nuestra tipificación de estructuras lingüísticas y narrativas y, en su caso, géneros como la parodia, que señalan textualmente la presencia de la ironía, por tratarse de una clasificación amplia y completa, donde se pueden advertir aspectos microestructurales de recursos lingüísticos, por ejemplo el énfasis semántico, y aspectos macroestructurales, que incluyen la parodia o un tipo de narrador específico.

Consideramos que encontramos evidencias lingüísticas que nos ayudan a encontrar el recurso de la ironía y comprender su función artística. De esta forma, se seguirá un esquema de trabajo representado visualmente por Leech y Short (1995: 14), que se reproduce en el siguiente esquema.

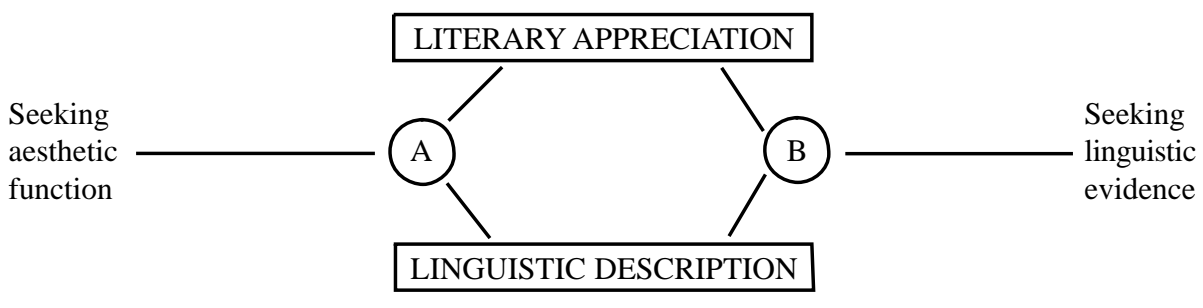

4. Aunque hay autores como Hutcheon (1981) y Frye (1973) que también hablan de la sátira. 
Leech (1974: 225) define a un lingüista como el que identifica tanto las características de un poema que necesitan interpretación como qué posibilidades de interpretación existen. Sin embargo, el crítico literario es el que sopesa las diferentes interpretaciones. Siguiendo el esquema anterior, al estudiar la ironía, nos centraremos en las estructuras narrativas y lingüísticas previamente especificadas, por lo que se utilizará más esa visión del lingüista que busca la evidencia lingüística. De esta manera, se analizará cómo funciona este recurso y en qué tipo y cómo puede clasificarse. Se descubrirá cómo estas estructuras permiten al lector utilizar su "stylistic competence" (Leech y Short 1995: 49), que le ayudará al lector descubrir y reconocer el estilo, irónico en este caso, de un autor. Pero, además, la visión del crítico literario nos permitirá interpretar la función estética y comprender mejor la figura retórica de la ironía en el texto literario.

\section{Bibliografía}

BANFIELD, Ann. Unspeakable Sentences. Narration and Representation in the Language of Fiction. Londres: Routledge \& Kegan Paul, 1982.

BOOTH, Wayne. A Rhetoric of Irony. Chicago: The University of Chicago Press, 1974.

- The Rhetoric of Fiction. (2nd ed.). Harmondsworth: Penguin, 1987.

— "Types of Narration." 1961. En: ONEGA, S. y J. A. GARCÍA LANDA (eds.). Narratology: and introduction. London: Logman, 1996, p. 145-155.

BRUMFIT, C. y R. CARTER. Literature and Language Teaching. Oxford: Oxford University Press, 1986.

DOMÍNGUEZ CAPARROS, José. "Literatura y actos de lenguaje". En: VAN DIJK, T. A. et al. Pragmática de la comunicación literaria. Madrid: Arco/libros, 1987, p. 83-121.

DUCROT, O. y T. TODOROV. Dictionnaire Encyclopédique des sciences du language. París: Seuil, 1972.

FABB, Nigel (comp.). La lingüística de la escritura: Debates entre lengua y literatura. Madrid: Visor, 1989.

— Linguistics and Literature. Oxford: Blackwell, 1997.

FLUDERNIK, Monika. The Fictions of Language and the Languages of Fiction. The Linguistic Representation of Speech and Consciousness. Londres: Routledge, 1993.

GARRIDO MEDINA, J. Lógica y Lingüística. Madrid: Síntesis, 1988.

GENETTE, Gerard. Narrative Discourse: An Essay in Method. Translated by Jane E. Lewin. Nueva York: Cornell UP, 1980.

- Figuras III. Barcelona: Lumen, 1989.

— Nuevo discurso del relato. Madrid: Cátedra, 1998. 
GIBSON, Walker. "Authors, Speakers, Readers, and Mock Readers". En: ONEGA, S. y J. A. GARCÍA LANDA (eds.). Narratology: and introduction. London: Logman, 1996, p. 155-161.

HALLE, Morris. "Un poema pictórico de la Biblia". En: FABB, Nigel (comp.). La lingüística de la escritura: Debates entre lengua y literatura. Madrid: Visor, 1989, p. 75-85.

HUTCHEON, Linda. Irony's Edge. The Theory and Politics of Irony. 1994. Londres: Routledge, 1995.

KERBAT-ORECCHIONI, Catherine. "L'ironie comme trope". Poetique, 1980, 41, p. 108-127.

LÁZARO CARRETER, Fernando. "La literatura como fenómeno comunicatica". En: VAN DIJK, T. A. et al. Pragmática de la comunicación literaria. Madrid: Arco/libros, 1987, p. 151-171.

LEECH, N. Geoffrey. A Linguistic Guide to English Poetry. Londres: Longman, 1974.

- y M. H. SHORT. A Style in Fiction. A Linguistic Introduction to English Fictional Prose. Londres: Longman, 1995.

LEVIN, Samuel R. "Consideraciones sobre qué tipo de acto de habla es un poema". En: VAN DIJK, T. A. et al. Pragmática de la comunicación literaria. Madrid: Arco/libros, 1987, p. 35-59.

LODGE, David. "Después de Bakhtin". En: FABB, Nigel (comp.). La lingüística de la escritura: Debates entre lengua y literatura. Madrid: Visor, 1989, p. 97-111.

LOZANO, Jorge; Cristina PEÑA MARÍN y Gonzalo ABRIL. Análisis del discurso. Hacia una semiótica de la interacción textual. Madrid: Cátedra, 1982.

MARCHESE, Angelo y Joaquín FORRADELLAS. Diccionario de retórica, crítica y terminología literaria. Barcelona: Ariel, 1986.

MARTIN, Wallace. Recent Theories of Narrative. Londres: Cornell University Press, 1986.

MUECKE, D. C. Irony and the Ironic. Londres: Methuen, 1986. (The critical idiom; 13).

OHMANN, Richard. "El habla, la literatura y el espacio que media entre ambas". En: VAN DIJK, T. A. et al. Pragmática de la comunicación literaria. Madrid: Arco/libros, 1987, p. 11-35.

ONEGA, Susana y José Angel GARCÍA LANDA. Narratology an introduction. Londres: Longman, 1996.

PRATT, Mary Louise. Toward a Speech Act Theory of Literature Discourse. Londres: Indiana University Press, 1977.

PRINCE, Gerald. "Introduction to the Study of the Narratee". En: ONEGA, S. y J. A. GARCÍA LANDA (eds.). Narratology: and introduction. London: Logman, 1996, p. 190-203. 
RIMMON-KENAN, Slomith. Narrative Fiction. Contemporary Poetics. Londres: Routledge, 1983.

SPERBER, Dan y Deirdre WILSON. "Outline of Relevance Theory". Links and Letters, 1994 a, 1, p. 85-106.

- Relevance, Communication and Cognition. Oxford: Blackwell, 1994 b.

VAN DIJK, T. A. et al. Pragmática de la comunicación literaria. Madrid: Arco/libros, 1987. 
